Discussion Papers
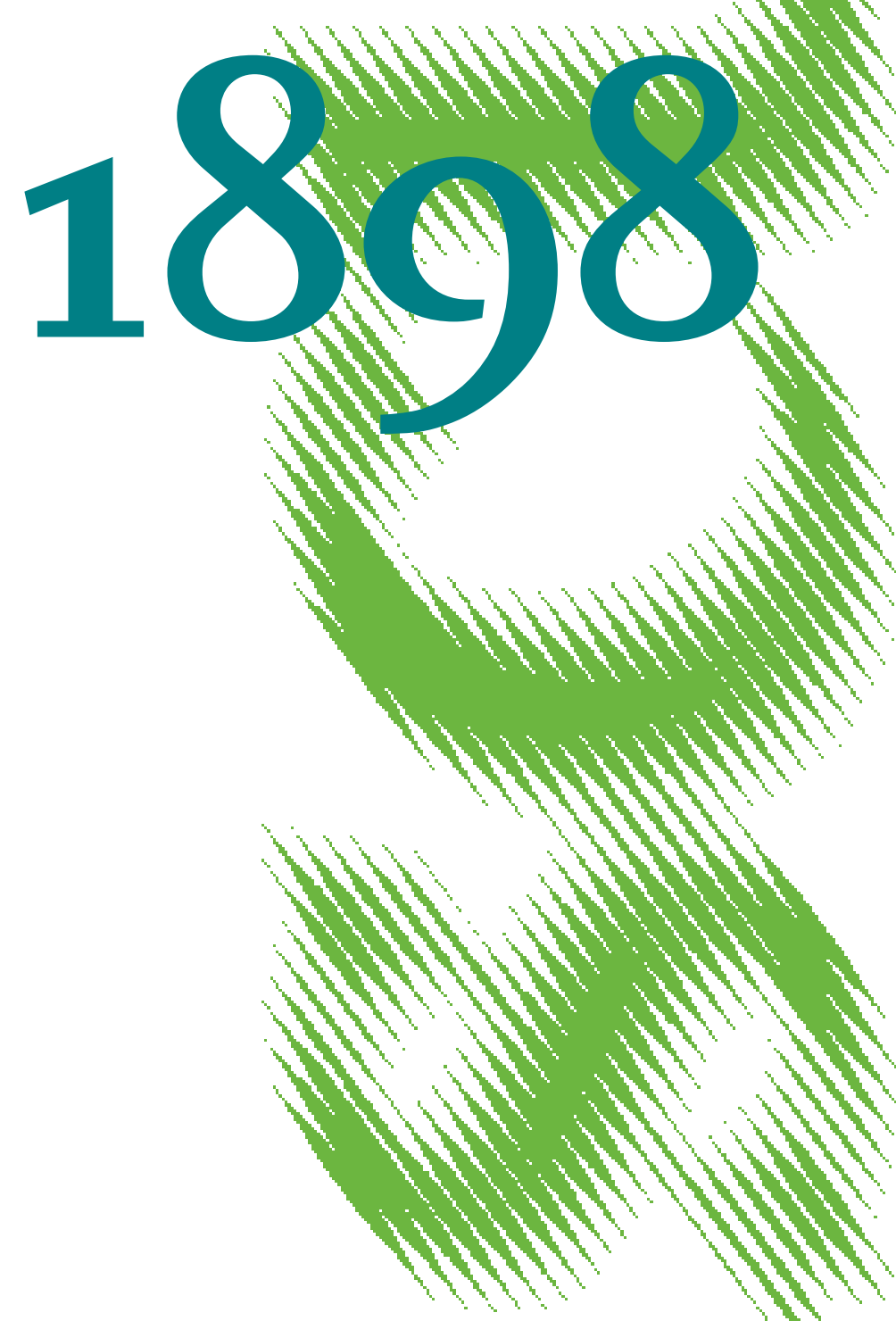

A Duration Approach for Estimating the Marginal Renewal Cost at German Motorways 
Opinions expressed in this paper are those of the author(s) and do not necessarily reflect views of the institute.

IMPRESSUM

(C) DIW Berlin, 2020

DIW Berlin

German Institute for Economic Research

Mohrenstr. 58

10117 Berlin

Tel. +49 (30) $89789-0$

Fax +49 (30) $89789-200$

http://www.diw.de

ISSN electronic edition 1619-4535

Papers can be downloaded free of charge from the DIW Berlin website:

http://www.diw.de/discussionpapers

Discussion Papers of DIW Berlin are indexed in RePEc and SSRN:

http://ideas.repec.org/s/diw/diwwpp.html

http://www.ssrn.com/link/DIW-Berlin-German-Inst-Econ-Res.html 


\title{
A duration approach for estimating the marginal renewal cost at German motorways
}

\author{
Neil Murray and Heike Link \\ German Institute for Economic Research (DIW Berlin), Department Energy, Transport, Environment
}

We estimate the marginal costs of road renewals as part of a social marginal cost scheme for road user charging. Within an analytical approach that mirrors the relationship between road deterioration, traffic load and road renewal, we use an accelerated failure time model for road pavement with the purpose to derive the effect from traffic increase on the length of road renewal cycles. Based on a comprehensive dataset for German motorways we fit a Weibull duration model with covariates such as traffic load from heavy vehicles as well as various control variables and derive the road deterioration elasticity with respect to heavy traffic. Similar to available studies for Sweden we find a deterioration elasticity below one, implying that Newbery's (1985) fundamental theorem does not hold for the German motorway network. The shape parameter of the Weibull function indicates that there is an ageing or weathering effect, and higher traffic loads are not the sole factor impacting on shorter pavement lifetimes. Our estimations yield a marginal renewal cost, which makes up approximately $40 \%$ of the average renewal cost. It implies that road user charges based on marginal costs will not yield a sufficient revenue to cover total costs.

Keywords: Duration model, accelerated failure time model, fundamental theorem, ma rginal cost, road transport

JEL classification: R42, R48, C41 


\section{Introduction}

Since more than two decades, the European Commission has been proposing to charge users of transport infrastructure the (short-run) social marginal cost they cause (CEC, 1998; CEC, 2001). This policy has initiated a stream of research dealing with the theoretical principles and the methodological and empirical foundations to estimate the single components of social marginal costs such as wear \& tear costs, congestion costs and the costs of air pollution, climate change, noise and accidents. The availability of both estimation methodologies and quantitative outcomes varies between these components and between modes of transport. For the road sector, extensive studies on optimal congestion and environmental charges as well as the respective cost estimates are available, but less attention has been paid to the estimation of marginal infrastructure costs such as the cost of operating, maintaining and renewing roads. The reason for this under-representation of marginal maintenance and renewal costs is the presumably lower quantitative importance of this type of cost compared to environmental, noise, accident, and climate costs. Furthermore, while the principle of marginal social costs is proposed as the relevant charging principle in the EU, infrastructure charges for road freight transport are based on average instead of marginal costs as defined in a series of EU directives (1999/62/62 EC; 2006/38/EC and 2011/76/EU). In contrast to this, the social marginal cost principle is defined as the leading principle for the rail access charging in the EU (see Directive 2001/14 EC), while cost recovery can be achieved by adding a mark-up to marginal costs if deemed necessary by the Member States. As a result, Sweden, France and Germany base their track access charges on marginal costs, with the latter two also applying Ramsey-based mark-ups. This policy has consequences on the frontier of research in estimating marginal costs: After some studies on road maintenance and renewal costs mainly during the first decade of this century, research on estimating marginal maintenance and renewal costs has since then focused on the rail sector.

This paper has been motivated to contribute to the sparse resea rch on estimating the marginal maintenance and renewal costs of roads as part of a social marginal cost pricing scheme. The focus lies on marginal renewal costs for two reasons. First, the cost of reconstruction and renewal constitutes the largest part of short-run road infrastructure cost. Second, the methodological and empirical challenges in estimating marginal renewal costs have so far pretended to conclude on 
a preferable estimation method and a sufficiently narrow range of estimates. The situation for roads is even more pronounced than for the rail sector, as we will show in our literature review. Against this background, we apply a duration modelling approach on a unique panel dataset on motorways in West Germany and use the estimated survival times between two pavement renewals as inputs to derive marginal cost estimates.

The reminder of this paper is organised as follows. Section 2 summarises the available literature on estimating marginal road infrastructure costs with a focus on renewal costs and on duration modelling. Sections 3 and 4 outline the methodology and the data used in this paper. Section 5 presents and discusses the modelling results. Section 6 offers some concluding remarks.

\section{Literature review}

The available research on estimating marginal infrastructure costs, e.g. the cost of operating, maintaining and renewing infrastructure, falls into two categories. The first category comprises cost function studies based on neoclassical production and cost function theory. The available studies seek to estimate a functional relationship between the observed cost of operating, maintaining and renewing infrastructure and the observed traffic volume, road characteristics and climate conditions ${ }^{1}$. The second stream of research is labelled as engineering approach or more precisely - duration approach. It uses physical measurements of road damages or road condition to estimate a functional relationship, a so-called lifetime or duration function, between these measurements and infrastructure characteristics, traffic volume and climate as explanatory variables. Since this paper deals with renewal costs, the following literature review focuses on renewal cost studies and in particular on duration approaches. Due to their methodological relevance for this paper, we also include studies for the rail sector. For an overview on marginal cost estimation for other components of infrastructure costs see Link (2015).

\footnotetext{
${ }^{1}$ In absence of data on factor inputs and input prices on a cross-sectional level, the majority of econometric cost function studies employ a single-equation approach and omit input prices, often with the additional argument that prices are homogeneous across regions or responsible units.
} 
Modelling renewal expenditures is challenging due to the characteristics of this cost category, e.g. its lumpy nature and its dependence on both past and current traffic. The traditional cost function approach suffers in this case from the lack of cross-sectional cost data over a sufficiently long period and from the presence of zero quantities in the years where no renewals were undertaken. There are relatively simple approaches to circumvent this problem: Andersson (2006) and Marti et al. (2009) combine maintenance and renewal costs in a single measure of total costs, Wheat and Smith (2008) eliminate the zeros by using more geographically aggregate data, and Link (2006) cumulates renewal costs and traffic over time. However, there are two alternative approaches, which aim to model the renewal process explicitly. The first is to apply corner solution models that are suitable for disaggregate data with a large proportion of zero values. Andersson et al. (2012) proposed the first study applying this approach for the analysis of track renewal costs in Sweden. Out of three corner solution models (Tobit, Heckit and a two-part model) the authors suggest the two-stage model (see Cragg, 1971) as the preferred one. This approach nests the Tobit model as a special case and takes account of the fact that the decision to participate in an activity (in this case the renewal of railways) may differ from the decision on how much to spend. The model consists of two parts where the first part can be written as a standard Probit model and the second part is a truncated regression model

The second approach is the afore-mentioned duration approach. It has been developed not only due to the difficulties with zero renewals, but also in order to embed renewal cost analysis in an engineering-based, theoretical understanding of traffic load, infrastructure deterioration and repair. The estimated change in pavement lifetime due to the change of traffic load affects the present value of future renewal costs and is thus the base for the marginal cost calculation. In contrast to the cost function approach, which uses observed road spending, the duration approach, as far as it is based on measurements of road condition, derives marginal costs from renewal requirements, irrespective of the actual expenditure on renewal

The first attempt to a comprehensive analytical model for the marginal cost of road goes back to the work of Newbery (1985). It was motivated by the question whether road maintenance costs should be allocated to road users based on efficient (e.g. marginal cost-based) or on equitable (e.g. average cost based) charges, and whether these two types of charges are quantitatively close 
to each other or not. Furthermore, Newbery (1985) raised the question whether an additional vehicle on the road imposes extra vehicle operating costs to other road users due to the road damage caused $^{2}$. The so-called fundamental theorem developed in this seminal paper is based on several assumptions such as a condition-responsive maintenance strategy ${ }^{3}$, no damaging effect of weather, equal age distribution of the roads, and constant traffic flows. It states that under these conditions the marginal cost of pavement resurfacing equals the average resurfacing cost, and that the extra vehicle operating cost imposed on other vehicles are negligibly small ${ }^{4}$. Relaxing some of these assumptions and taking account of weather effects and traffic growth reduces marginal costs below average costs, whereby the degree of this reduction depends on the damage relationships used in the calculations. Newbery (1985) uses results from the AASHTO road test, which will be discussed below. With this database, he shows that weathering reduces the marginal cost to a range of $75-90 \%$ of average costs in dry climates and to an even lower share in more severe climate conditions. Traffic growth at low-volume roads reduces marginal cost further, but for high-volume roads, the ratio between marginal costs and average costs increases. Newbery's (1985) analytical approach provides a convenient shortcut and computation tool where parameter values can be chosen out of available engineering experience or road pavement test data.

Before discussing further studies based on Newbery's (1985) findings, we briefly review the approaches for deriving vehicle-damage relationships which form an important ingredient when predicting marginal costs. Vehicle-damage relationships can be derived either from experimental pavement failure data, or from in-service pavement data. The probably most prominent example of a duration study employing the first type of data is the AASHTO road test (Highway Research Board 1961). This experimental study was designed as an accelerated pavement test where variously loaded vehicles in different vehicle- and axle-combinations (e.g. single vehicles, vehicles

\footnotetext{
2 Such a road damage externality would be present if a vehicle damages the road surface, which increases its roughness, and thereby increases the vehicle operating cost of subsequent vehicles.

${ }^{3}$ A condition-responsive maintenance strategy means that the road authority decides to resurface any particular road when it reaches a predetermined trigger value of roughness.

${ }^{4}$ Such road damage externality is caused when a vehicle damages the road surface and increases its roughness, and thereby increases the vehicle operating cost of subsequent vehicles.
} 
with trailers, articulated vehicles) were driven on different types of road surfaces ${ }^{5}$. The most important conclusion from this test was the so-called fourth power rule, which states that the damaging force is approximately proportional to the fourth power of its load. There is an extensive literature discussing various problems of the AASHTO road test. Apart from the experimental design and problems of transferability to other geographic and climatic context, the lack of treating the dataset ${ }^{6}$ based on a censored structure raised critique. Small and Winston (1988) and Small et al. (1989) used the condition measurements from the original AASHTO test data to re-estimate the life-time of roads as the interval between necessary pavement resurfacings, depending on road thickness, traffic load and aging (weathering effect), accounting for the censored nature of his data by means of a Tobit model. Their results suggest that the lifetime of roads is shorter than the AASHTO-based design life, and that the relation between pavement life and axle-load follows rather a third-power law than the original fourth-power law. Ozbay et al. (2001) refers to Small et al.'s (1989) work and estimates marginal resurfacing costs apparently based on a similar approach for the Northern New Jersey highway network. Prozzi and Madanat (2004) use the ASHTO test data and estimate a damaging power of 4.15 when using a random effects model. Anani and Madanat (2010a) discuss further dependency of the fourth power rule from the definition of road deterioration as the loss in serviceability. They show that using different indicators of road deterioration such as roughness, cracking or rutting leads to different vehicle-damage relationships.

The resources to conduct large-scale experiments of this type are rather limited ${ }^{7}$. However, both in the US and in Europe technical equipment and human resources to conduct frequent road condition measurement for in-service roads are available. This implies that in-service pavement data such as the FHWA long-term pavement performance data in the US, the Swedish Long Term

\footnotetext{
${ }^{5}$ The ASHTO road test was preceded by a pavement test in Maryland (so-called Maryland test, see Williams and Lee, 1958) and by the so-called WASHO-test (see Miller, 1953).

${ }^{6}$ Despite of rather high levels of load and kilometres driven, many of the pavements did not reach the failure criteria during the timeframe of the test and the respective values were extrapolated.

${ }^{7}$ Newbery (1988) estimates that a replication of the AASHTO road test would cost over $\$ 300$ million at 1980 prices. Hofko and Blab (2009) have developed a strategic plan for a European road experiment called EURODEX. To the best of our knowledge, this plan has never been realised, presumably due to the high cost of it.
} 
Pavement Performance (LTPP) data and the German ZEB road condition data (ZEB-data, see BASt, 2015) can increasingly be employed for duration studies.

Newbery's (1985) fundamental theorem and the subsequent work such as Newbery $(1988,1990)$ have been used as a point of departure for refined research on estimating marginal road maintenance and renewal costs. Within a comprehensive model on the social costs of road use for both congested and non-congested roads, Small et al. (1989) obtain marginal costs that are higher than average costs due to the weather effect. Anani and Madanat (2007) treat the deterioration factor, expressed as ESAL to failure as stochastic while leaving annual loading (ESAL per year) constant. Anani and Madanat (2010b) refine the model by introducing multiple maintenance measures instead of considering the dominant one only and show that marginal cost are higher in this case. While the US studies are based on the AASHO road test damaging factors (the ESALs), there are two Swedish studies based on in-service pavement data. Lindberg (2002) provides an empirical test of Newbery's fundamental theorem based on the aforementioned Swedish data on road condition (using in particular the cracking and roughness index) and traffic volume. This work introduces the concept of a deterioration elasticity that expresses the changed lifetime of pavement induced by changes in traffic load. Lindberg's (2002) model assumes that all road damage is due to traffic (no weathering effect) and that the age of roads is equally distributed, and in contrast to the fundamental theorem, the model allows for growing traffic $^{8}$. Under these assumptions, the marginal cost of resurfacing an average road is a product of the average cost and the deterioration elasticity. Lindberg (2002) yields a deterioration elasticity that is below unity, suggesting a weaker relationship between traffic and pavement lifetime than the fundamental theorem implies. This work has been further developed in Haraldsson (2007) where Lindberg's (2002) assumption that road damage is deterministic and proportional to traffic load (cumulative axles) is replaced by a lifetime function that is estimated by a survival (or duration) model. Haraldsson (2007) uses AADT for HGV and passenger cars instead of standard axles. Surprisingly few research has since then been conducted to develop this conceptual framework further and to test it for different national road data. Apart from

\footnotetext{
${ }^{8}$ As mentioned earlier, Newbery (1985) introduces climate and traffic growth in an extended version of his analytical model.
} 
Haraldsson's (2007) application to Swedish roads, the concept has only been used in Andersson et al. (2016) to estimate marginal renewal costs for the Swedish rail network.

The final part of this literature review refers to the econometric core of our paper, which employs a duration model (or labelled differently: survival, time to event, failure time model). It is beyond the scope of our paper to review the extensive literature on duration (survival) models in various fields such as medicine, engineering, economics, political sciences and sociology. A summary of the major principles and applications in transportation research is given in Bhat (2020) and in Hensher and Mannering (1994), though these two sources do not give any reference to analysing lifetime distributions for transport infrastructure. However, engineering practice and reliability literature provide various applications of lifetime distributions. Out of the issues discussed there, the choice of the general approach (parametric models versus non- or semi parametric models), the choice of the hazard function (proportional hazard versus accelerated failure time, see for example Mendes and Fard, 2014) provide relevant inputs into our analysis. Because reliability testing is an accelerated lifetime testing, the most commonly used approach has been the accelerated failure time model (see Dupuy, 2014 for an overview on accelerate failure time models in reliability analysis). The most widely used distribution in this field has been the Weibull model (see for example Prozzi and Madanat, 2000; Peng et al., 2013; Anani and Madanat, 2007) out of various forms such as normal, log-normal, log-logistic, or gamma. Engineering literature provides further interesting avenues for estimating duration models, which, however, are currently beyond the scope of our work considering the nature of our data. In this context, we mention two points that seem relevant for further research with improved data: First, the treatment of competing risks and multiple failure modes. Second, the integrated modelling of soft failure, e.g. the degradation of the tested facility, and hard failure, e.g. the breakdown or collapse of the tested facility (see for example modelling soft failure as a gamma process and hard failure by a Weibull survival function in Mireh et al., 2019). 


\section{Methodology}

\subsection{Duration Model}

We focus on analyzing the length of time that elapses from time $x_{i}$, defined either as the construction or as the renewal date of a road section, until the next renewal date $x_{i+1}$ or until the end of the observation period which may precede the termination of the renewal intervals. The underlying assumption that a renewal is carried out if the section has deteriorated to a quality level that requires replacement, implies that the interval $\left[x_{i}, x_{i+1}\right]$ measures the lifetime of the road section. For the duration analysis of the road section's service life we use an accelerated failure time model based on a Weibull survival function and relevant covariates. This approach is based on the theoretical foundation provided in Klein und Moeschberger (2006).

We commence with the definition of a survival function, which states the probability that the lifetime of a road sections exceeds the time $x$. Formally the function is described as

$$
S(x)=\operatorname{Pr}(X>x)
$$

where $X$ characterizes a non-negative random variable given by the observed lifetime of the road section. Since $X$ is a continuous random variable, the distribution refers to the survival function by

$$
S(x)=1-F(x)=1-\operatorname{Pr}(X \leq x)
$$

The probability density function $f(x)$, which identifies the unconditional probability of a road section requiring renewal at time $x$, is

$$
\begin{aligned}
& S(x)=\operatorname{Pr}(X>x)=\int_{x}^{\infty} f(x) d s \\
& f(x)=-\frac{d s(x)}{d x}
\end{aligned}
$$


A related useful function is the hazard function which determines the probability that a road section operated up to time $x$ will fail and must be renewed in the next instant $\Delta x$. The hazard function is expressed by

$$
h(x)=\lim _{\Delta x \rightarrow 0} \frac{P[x \leq X<x+\Delta x \mid X \geq x]}{\Delta x}
$$

and yields for $X$ being a continuous random variable

$$
h(x)=\frac{f(x)}{S(x)}=\frac{-d \ln [S(x)]}{d x}
$$

Respectively the cumulative hazard function is defined as

$$
H(x)=\int_{0}^{x} h(u) d u=-\ln [S(x)]
$$

Following reliability literature, we apply a parametric Weibull model. This distribution allows to describe processes with memory and is highly flexible in allowing different shapes of the survival function and in nesting the exponential and the Rayleigh distribution. The underlying Weibull survival function for $x>0$ is given by

$$
S(x)=\exp \left[-\lambda x^{\alpha}\right]
$$

where the scale parameter $\lambda>0$ and the shape parameter $\alpha>0$ indicate the functional form. The shape parameter $\alpha$ determines the properties of the hazard rate with $\alpha<1$ implying a timedecreasing hazard, $\alpha=1$ a constant hazard rate and $\alpha>1$ an increasing hazard rate over time. If $\alpha$ takes values above 2 than the hazard function increases more than proportionally with time which can be interpreted as aging or - in our case - also as weathering effect.

The respective hazard function $h(x)$ and the cumulative hazard function $H(x)$ are described by

$$
h(x)=\alpha \lambda x^{\alpha-1}
$$




$$
H(x)=\lambda x
$$

The probability density function $f(x)$ and cumulative distribution function $F(x)$ are given as

$$
\begin{aligned}
& f(x)=\alpha \lambda x^{\alpha-1} \exp \left(-\lambda x^{\alpha}\right) \\
& F(x)=1-\exp \left[-\lambda x^{\alpha}\right]
\end{aligned}
$$

Finally, the expected lifetime of a road section is defined by

$$
E(x)=\mu=\left[\Gamma\left(1+\frac{1}{\alpha}\right)\right] \lambda^{-1 / \alpha}
$$

where $\Gamma[\alpha]$ relates to the Gamma function

$$
\Gamma[\alpha]=\int_{0}^{\infty} u^{\alpha-1} e^{-u} d u
$$

The accelerated failure time model derived in this section can be expressed as a log linear regression equation which includes relevant covariates (Klein and Moeschberger, 2003). This model with covariates, out of which the most important one is traffic volume, enables us to predict the deterioration elasticity which is the most important parameter for the estimation of marginal renewal costs. The model will be described in detail in section 5.1.

\subsection{Approach for estimating marginal renewal costs}

Our interest is to establish an analytical relationship between the change in the present value of future renewals caused by a marginal increase in traffic, in the spirit of Newbery's (1985) model and Lindberg's (2002) definition of a deterioration elasticity which we derive from our Weibull duration model. For the analytical derivation of marginal renewal costs we use the approach from 
Andersson et al. (2016) or Haraldsson (2007) who calculated marginal costs in the context of rail track and road pavement renewals respectively.

We follow their approach and first assume that every road section begins its service life with an initial physical quality $\Phi^{H}$. Subsequently, the road experiences a quality decrease during its service life primarily due to traffic degradation and possibly to some extent due to the passage of time (aging and weathering). Andersson et al. (2016) assume that the functional form underlying the degradation process to be a linear function of cumulative traffic volume multiplied by a nonlinear function that accounts for weather and climate effects (represented for example by an exponential factor as suggested by Small et al., 1989). The deterioration of road quality progresses continuously up to a point $\Phi^{L}$ where this section cannot any longer sufficiently meet the predefined serviceability requirements and must be renewed, which consequently recovers the roads quality to $\Phi^{H}$. If this process is repeated in perpetuity and if we assume a constant volume of traffic $\bar{q}$, the resulting services lives are accordingly all of length $\bar{X}$ (See solid curve in figure 1 ). Given the functional form of the degradation process, the costs of road renewals $c$, and the social discount rate $r$, the present value of such an infinity cycle of renewals $(n)$ can be written as:

$$
\lim _{n \rightarrow \infty} P V C_{X}=c \frac{1}{\left(1-e^{-r \bar{X}}\right)}
$$

The basic idea to derive marginal renewal costs is to consider a short-term increase of traffic (e.g. a shock) at time $\tilde{x}$ during the first life-cycle, which changes initial traffic volume $q$ to $q_{\tilde{x}}=q+\Delta q$. Due to this increase in traffic, the road quality degrades faster and consequently, the renewal in period 1 will be scheduled at an earlier point $X\left(\right.$ Where $X<X^{*}$ ). Assuming further that the shock only persists within the first renewal interval and traffic volume will be constant in all subsequent intervals, all intervals but the first one will still be of length $\bar{X}$ but are renewed at an earlier point in time (See dotted curve in figure 1). It should be noted that this is a rather strong assumption (for a critique see Anani and Madanat, 2007) but for the moment it offers a relatively convenient approach to the problem.

Accordingly, the present value of a road section observed at point $\tilde{x}$ is then given as:

$$
P V C_{\tilde{x}}=c e^{-r \omega} \frac{1}{\left(1-e^{-r \bar{X}}\right)}
$$




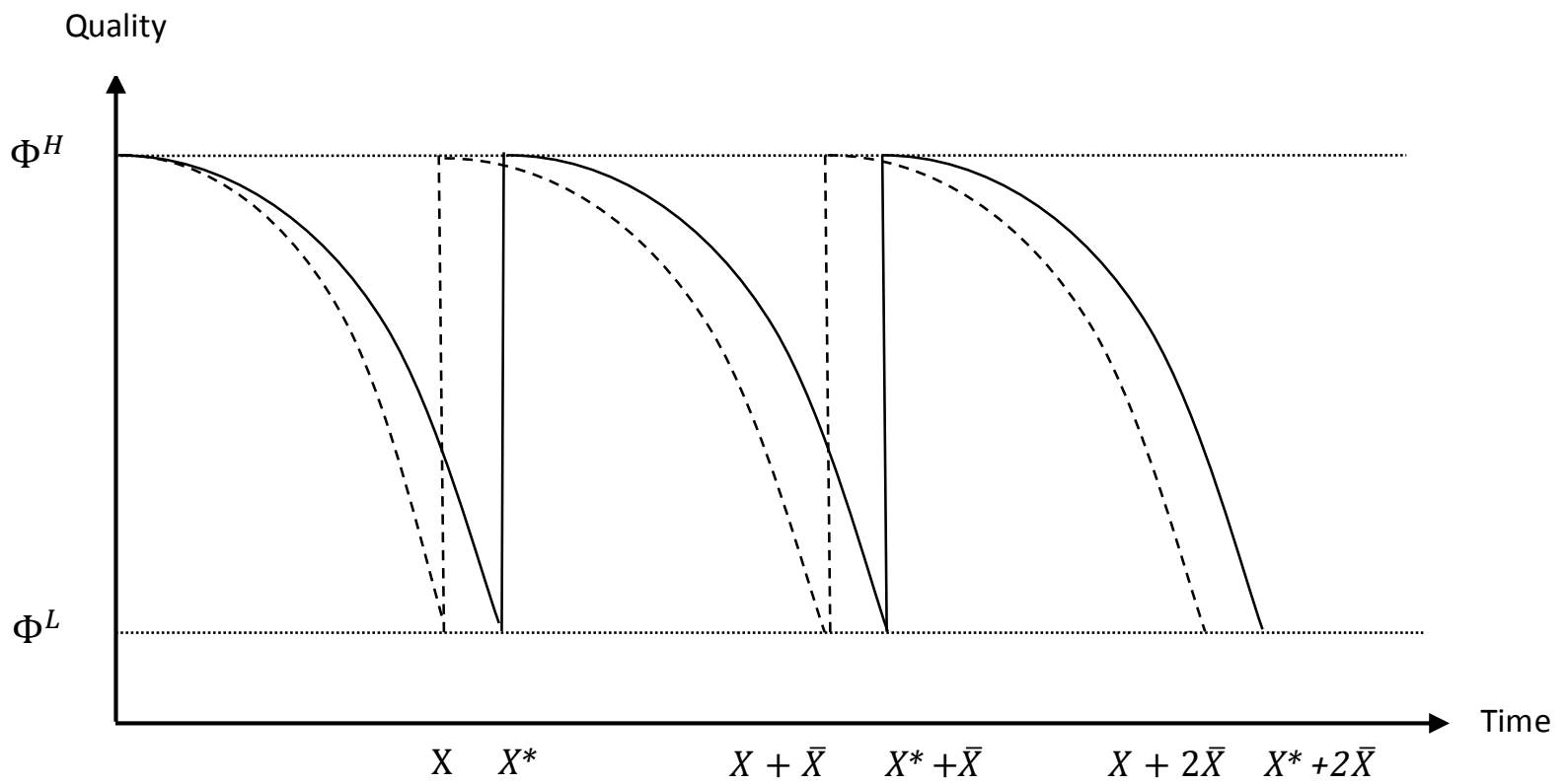

Figure 1: Roadway Service Lives with marginal Traffic Increase (Graph according to Andersson et al. 2016)

The first part of the equation relates to the present value of the current service life $\mathrm{X}$ where $\omega=$ $\mathrm{X}-\tilde{X}$ indicates the remaining time to the next renewal. The second part accounts for all future renewal intervals of length $\bar{X}$. The marginal costs are given as the change in present value due to the increased traffic volume, hence obtained by taking the derivative of $P V C_{\tilde{x}}$ with respect to $q_{\tilde{x}}$

$$
M C_{\tilde{x}}=\frac{\partial P V C_{\tilde{x}}}{\partial q_{\tilde{x}}}=\frac{\partial P V C_{\tilde{x}}}{\partial X} \frac{\partial X}{\partial q_{\widetilde{x}}}=-c r \frac{e^{-r \omega}}{\left(1-e^{-r \bar{X}}\right)} \frac{\partial X}{\partial q_{\tilde{x}}}
$$

Under the above assumption that the marginal cost is caused by a shock on an otherwise stable traffic flow, Haraldsson (2007) rewrites this in terms of a change in average annual traffic during the first renewal interval $\left(\bar{q}_{1}\right)$. He shows that a one-unit change of traffic at $\widetilde{x}$ changes average traffic over the entire period by approximately $1 / X$. We follow this approximation but use cumulative trafficin renewal period $1\left(\bar{q}_{1}\right)$. The last part in equation (18) can then be rewritten as:

$$
\frac{\partial X}{\partial q_{\tilde{X}}}=\frac{\partial X}{\partial \bar{q}_{1}} \frac{\partial \bar{q}_{1}}{\partial q_{\tilde{x}}}=\frac{\partial X}{\partial \bar{q}_{1}} \frac{1}{X}
$$

Introducing the deterioration elasticity, which gives the percentage change in service life associated with a percentage change in traffic volume within the first renewal period as

$$
\varepsilon=\frac{\partial X}{\partial \bar{q}_{1}} \frac{\bar{q}_{1}}{X}
$$

and combining equations (18), (19) and (20) yields: 


$$
M C_{\tilde{x}}=\frac{\partial P V C_{\tilde{x}}}{\partial q_{\tilde{x}}}=-c r \frac{e^{-r \omega}}{\left(1-e^{-r \bar{X}}\right)} \frac{\varepsilon}{\bar{q}_{1}}
$$

While in equation (21) renewal intervals are deterministic, we assume now that they follow a probability density g

$$
E\left[M C_{\tilde{\chi}}\right]=-\operatorname{cr} \frac{\varepsilon}{\bar{q}_{1}} \int_{0}^{\infty} \frac{e^{-r \omega}}{\left(1-e^{-r \bar{X}}\right)} g(\omega) d \omega
$$

Based on the Weibull survival function derived in section 3.1 (Eq. (9)), the probability density can be expressed as $g(\omega)=\frac{e^{-\lambda \omega^{\alpha}}}{\mu}$ and the deterioration elasticity $\varepsilon$ corresponds to the coefficient of cumulative heavy vehicles in the later Weibull regression $\beta_{H V}$. Including this in equation (22) leads to the final form of marginal costs:

$$
E\left[M C_{\tilde{x}}\right]=-\beta_{H V} \frac{C}{\bar{q}_{1} \mu_{i}} \frac{r}{\left(1-e^{-r \bar{X}}\right)} \int_{0}^{\infty} e^{-r \omega-\lambda_{i} \omega^{\widehat{\alpha}}} d \omega
$$

This equation can be separated into four factors, which are necessary for the calculation of marginal costs. The first part represents the deterioration elasticity of heavy vehicles $\beta_{H V}$ which is estimated based on the Weibull duration model. The second part of the formula, the term $\frac{C}{\bar{q}_{i} \mu_{j}}$ accounts for the average renewal cost per kilometer of heavy vehicles. Accordingly, $C$ indicates the sum of all available renewal costs divided by the sum of all replaced highway kilometers, $\bar{q}_{1}$ indicates the yearly average traffic of heavy vehicles and $\mu_{i}$ the estimated service life given in years which is calculated as $\mu_{i}=\exp \left(X_{i}{ }^{\prime} \beta\right)$. The third part of equation (22), the term $\frac{r}{[1-\exp (-r \bar{X})]^{\prime}}$ discounts the marginal costs based on an infinite cycle of average service lives $\bar{X}$, which is defined as $\bar{X}=\mu_{i} \Gamma\left(1+\lambda_{i}\right)$ with $\lambda_{i=} \frac{\mu_{i}}{\widehat{\alpha}}$ as the individual scale parameter and $\hat{\alpha}$ as the model-specific shape parameter. Finally, the last part of the equation forms an integral that corrects the marginal cost estimate according to the underlying distribution of the observed road service lives. The integral is solved numerically for the remaining lifetime $\omega$, whereby we set the upper limit of the integral to 50 years, since the maximum age of a section in our sample is 34 years. 


\section{The data}

For our econometric analysis we used three different data sources, two of which contain information on the renewal dates of motorway sections and one data set providing measurements of traffic volume. Each observation in these data sets corresponds to one distinct motorway section. Furthermore, each section consists of two directions, which we treat both as individual observations. The data refer to West Germany only since extraordinary high maintenance and renewal expenditures spent in East Germany after the German re-unification would bias the results.

Our first data set originates from a historical data collection project of the engineering consultants ASTRA, carried out on behalf of the German Ministry of Transport BMVI (ASTRA, 2001). It covers the period from 1935 to 2000 and contains a description of all renewal measures regarding length and type of measure, material used and thickness of layers concerned. This physical description was evaluated with unit costs for each type of construction to express the measures in monetary terms. ${ }^{9}$ The second dataset originates from Maerschalk et al. (2017) and documents - among other variables - from the perspective of 2015 (the year of analysis in this project) the date for the chronologically last renewal on German motorway sections. Again, the type of measure, the thickness of layers and the material used was available, and it was monetized using the same procedure as for our first dataset by the engineering consultants Maerschalk \& Krause. We have matched these two datasets into a unique sample containing information on renewal measures for a total of 80 consecutive years, starting in 1935 and ending in 2015 for West German motorways. In addition, we have completed the information by including the date of initial construction for each motorway segment ${ }^{10}$. Both data sources report renewal measures for all road layers concerned. As in any case the road surface will be renewed, we used all reported

\footnotetext{
${ }^{9}$ This was carried out by one of the leading engineering consultancies in the field of pavement management systems in Germany (SEP Maerschalk).

10 Plausibility checks were carried out whether we have missed measures between 2000 from the ASTRA database and the last measure before 2015 from Maerschalk et al. (2017). If the condition measurement on the respective section was below the trigger value during this period we have assumed that no renewal took place, otherwise we deleted the observation.
} 
measures to define the renewal interval. This means that the intervals we analyse refer to resurfacing, independent of the fact whether in the same measure also other road layers were renewed. To account for the fact that multiple renewal activities as compared to resurfacing only will impact on service life, we include dummies in the regression model that indicate the type of renewal. The richness of our data would potentially allow analyzing lifetimes of other road layers, too, but would require separate cost data.

The matched renewal data consists of 2288 individual motorway sections, each of which has undergone at least one and at most three renewal intervals during the 80 year's observation period. We treat repeated (multiple) intervals on the same section as individual and independent observations. If an interval does not end with a renewal by 2015, it is censored to the right using an event dummy. Data treatment was in particular necessary for some implausibly short service lives, which are very likely due to warranty rights if the road section is not renewed appropriately. These observations would introduce a bias into our model since the service life is not determined by traffic loads or structural variables, but by inadequate renewal work. Therefore, we removed intervals shorter than four years, which is a common time frame for warranty rights on road structures to be built. In addition, we removed censored observations with an interval starting in 2015 , as the life span in this case would not exceed zero years.

Traffic data was added from a third dataset provided by the Federal Highway Research Institute (BASt). This source covers the average daily traffic volume (AADT) from 1980 to 2015 and distinguishes between passenger cars and heavy traffic (HV), with the latter defined as all vehicles above 3.5 tons (see Fitschen und Nordmann, 2012 for more details on the methodology of traffic counts on German motorways) ${ }^{11}$. Out of this data we matched the AADT of heavy vehicles to our renewal data based on the results of a workshop with road engineering experts, who argued that regular cars only play a minor role in the degradation of road surface. Gaps in traffic count data were estimated using growth rates of traffic volume in the respective federal state. Based on the

\footnotetext{
${ }^{11}$ This means that buses are included. While this requires further calculations when deriving road user charges per vehicle class, the inclusion of buses is justified for the purpose of our analysis due to their contribution to road damage.
} 
matched AADT, we created the variable HV (Heavy Vehicles) which indicates the cumulated heavy traffic that each motorway section accommodated within a service life.

The more restricted availability of traffic data (starting in 1980 as compared to renewal data starting in 1935) implies that our final sample includes intervals that start at 1980 or later. This leaves us with a sample of 1822 intervals from which 1302 are right censored and 520 are completed.

Table 1 provides an overview on the descriptive statistics of our variables. The variable Duration measures the service life of motorway sections, defined as the time between two renewals and the time between construction and renewal, respectively. It should be noted that the existence of right-censored observations introduces a downward bias since these observations do not cover the entire life cycle. Therefore, we show descriptive statistics for both a subsample of uncensored observations and for the whole sample including censored data with the latter being used in our duration modelling. Further explanatory variables that are included as control for structural

Table 1: Descriptive Statistics

\begin{tabular}{|c|c|c|c|c|c|c|}
\hline Statistic & Mean & St. Dev. & Min & $\operatorname{Pctl}(25)$ & $\operatorname{Pctl}(75)$ & Max \\
\hline \multicolumn{7}{|c|}{ Uncensored Observations $(N=520)$} \\
\hline Duration (years) & 16.51 & 7.77 & 4 & 11 & 22 & 34 \\
\hline Section Length $(\mathrm{km})$ & 4.84 & 3.27 & 0.29 & 2.31 & 6.65 & 23.03 \\
\hline HV (mill.) & 20.88 & 17.29 & 0.79 & 8.44 & 27.99 & 105.42 \\
\hline Number of Lanes & 2.32 & 0.49 & 2 & 2 & 2.9 & 4 \\
\hline SMA & 0.70 & 0.46 & 0 & 0 & 1 & 1 \\
\hline Dummy T1 & 0.47 & 0.50 & 0 & 0 & 1 & 1 \\
\hline \multicolumn{7}{|c|}{ Censored Observations $(N=1,302)$} \\
\hline Duration (years) & 15.77 & 9.45 & 1 & 7 & 23 & 34 \\
\hline Section Length $(\mathrm{km})$ & 4.26 & 3.12 & 0.10 & 1.90 & 6.03 & 15.82 \\
\hline HV (mill.) & 24.85 & 21.97 & 0.52 & 8.13 & 34.73 & 112.03 \\
\hline Number of Lanes & 2.30 & 0.45 & 2 & 2 & 2.8 & 4 \\
\hline SMA & 0.57 & 0.50 & 0 & 0 & 1 & 1 \\
\hline Dummy $\mathrm{T} 1^{12}$ & 0 & 0 & 0 & 0 & 0 & 0 \\
\hline
\end{tabular}

variables in our Weibull model are the section length, the number of lanes, and dummies for the

\footnotetext{
12 The first renewal interval for every motorway section is uncensored and covers the time span elapsed between the initial construction and first maintenance. This implies, that T1 can only be 0 for censored intervals.
} 
corresponding federal state (omitted in table 1). Moreover, we add a dummy indicating whether the surface layer of the roadway was built using stone mastic asphalt, which has proven to be more durable than other materials (see Rosauer, 2010). Exploratory analysis of the data revealed that the first life period appears to have a significantly higher durability compared to subsequent renewal periods. Therefore, we include a dummy $T 1$ that records whether the observed duration was the result of the first renewal period on this section. As mentioned above, we account for the impact of renewals of various road layers versus resurfacing only by introducing dummies ${ }^{13}$ for the type of measure.

The mean duration of a motorway pavement is 15.8 years (in the total sample, e.g. censored) and 16.5 years respectively (in the uncensored subsample which contains only completed renewal intervals). The mean section length of 4.3 and $4.8 \mathrm{~km}$ respectively show the highly disaggregated quality of our data. An average motorway section is passed by almost 21 mill. vehicles above $3.5 \mathrm{t}$ within a service life, when including the censored observations this figure is even almost 25 million heavy vehicles. This difference stems from the increased traffic volume over the past decades, which is reflected by the average starting year of intervals (1999 in the censored sample compared to 1988 in the uncensored sample).

Furthermore, the total number of intervals available per roadway section can vary between one and a maximum of three intervals. Within the dataset we observe 1060 roadway sections with one interval, 369 observations with two intervals, and finally, 8 sections that comprise three intervals. Stone mastic asphalt is used as the surface layer in 1108 roadway sections.

\section{Discussion and Results}

\subsection{Duration Model}

The computation of marginal cost in equation (16) requires estimates from the stochastic Weibull duration model for the lifetime of road pavements. The necessary parameters to be estimated are the deterioration elasticity $\varepsilon$, the shape and scale parameter $\alpha$ and $\lambda_{i}$, and finally the expected lifetimes $\mu_{i}$. Based on the accelerated failure time model derived in Section 2.1, we define the regression equation according to Klein and Moeschberger (2003) as:

\footnotetext{
${ }^{13} \mathrm{~A}$ total of eight dummies correspond to the type of renewal such as thin-layer pavement renewal or base course renewal.
} 


$$
\ln \left(x_{i}\right)=\beta_{0}+z_{i}^{\prime} \beta+u_{i}
$$

where $z$ indicates a vector of covariates. These include the accumulated heavy traffic HV expressed in logs, and additional control variables that relate to the structural characteristics of a motorway section $i$ such as length, number of lanes, the dummy for material (SMA), the dummy for the first renewal interval on a section if multiple intervals are observed, federal state dummies, and finally dummies for the type of renewal. Since the response and explanatory variables are both treated in logs, the model has the convenient property that the coefficients can be interpreted as elasticities, and therefore, the coefficient $\beta_{H V}$ directly relates to the deterioration elasticity $\varepsilon$. We expect HV to be our most important covariate having a negative correlation with the survival time of road pavement. Furthermore, we expect the number of lanes having a positive effect on pavement lifetime because traffic can distribute amongst lanes leading to more observed intervals with longer lifetimes for lanes used more intensively by lighter vehicles. Based on exploratory analysis and engineering literature, we expect a positive impact of the first renewal interval on duration as well as a positive impact of using stone mastic asphalt (SMA). The error term $u_{i}$ follows an extreme value distribution with the shape parameter $\hat{\alpha}$. It should also be mentioned that the raw coefficients of a Weibull regression do not offer a clear and meaningful interpretation (Klein Moeschberger, 2003, Chapter 12). Therefore, they are transformed according to $\beta=-\hat{\alpha} \psi$ where $\hat{\alpha}$ represents the shape parameter and $\psi$ the original regression coefficients.

We estimate the model by maximizing the following log-likelihood function in the presence of censored data:

$$
\ln L(\theta)=\sum_{i=1}^{N}\left\{d_{i} \ln \left[f\left(x_{i} \mid z_{i} ; \theta\right)\right]+\left(1-d_{i}\right) \ln \left[1-F\left(x_{i} \mid z_{i} ; \theta\right)\right]\right\}
$$

with $d_{i}$ as a dummy indicating censoring, $z_{i}$ as a vector of covariates for observation $i$, and $\theta$ a vector of model parameters that require estimation. All calculations were performed using $R$ ( $v$. 4.0.2). 
We have estimated two separate Weibull regression models that differ with respect to the inclusion of traffic. Model 1 contains the traffic variable as single term, whereas Model 2 includes an additional quadratic interaction term of traffic to reflect a possible nonlinear effect.

\section{Dependent variable:}

Duration

\begin{tabular}{|c|c|c|}
\hline & & Duratio \\
\hline & Model 1 & Model 2 \\
\hline Shape & 2.575 & 2.572 \\
\hline & $(0.034)$ & $(0.034)$ \\
\hline $\log \mathrm{HV}$ & $-0.845^{* * *}$ & 1.607 \\
\hline & $(-0.059)$ & $(-1.379)$ \\
\hline$(\log H V)^{2}$ & & $-0.075^{*}$ \\
\hline & & $(-0.042)$ \\
\hline Number Lanes & $0.944^{* * *}$ & $0.983^{* * *}$ \\
\hline & $(-0.109)$ & $(-0.111)$ \\
\hline Period 1 & $1.303^{* * *}$ & $1.295^{* * *}$ \\
\hline & $(-0.111)$ & $(-0.111)$ \\
\hline SMA & $0.662^{* * *}$ & $0.644^{* * *}$ \\
\hline & $(-0.115)$ & $(-0.116)$ \\
\hline Length & $0.051^{* * *}$ & $0.054^{* * *}$ \\
\hline & $(-0.014)$ & $(-0.014)$ \\
\hline Federal State Dummies & Yes & Yes \\
\hline Renewal Type Dummies & Yes & Yes \\
\hline Observations & 1,822 & 1,822 \\
\hline Log Likelihood & $-2,150.58$ & $-2,148.90$ \\
\hline LR Test Statistic & 590.00 & 593.00 \\
\hline
\end{tabular}

Note: The model includes a constant, which is however not displayed within the transformed output. Coefficients of the federal state dummies and renewal type dummies are omitted in the output for better readability but available on request. Standard Errors are given in parentheses and statistical significance is indicated by asterisks where* $\mathrm{p}<0.1 ;{ }^{* *} \mathrm{p}<0.05 ;{ }^{* * *} \mathrm{p}<0.01$

We evaluate the two models based on the likelihood ratio test statistics and an analysis of the Cox-Snell residuals, which should follow a $45^{\circ}$ line when plotted against the cumulative hazard functions $H(x)$ if the model is correctly specified (see Klein and Moeschberger, 2003). 
Table 2 shows the estimation results of the two Weibull models. With overall plausible and significant estimates in both models, the results differ regarding our main variable of interest, the traffic volume. While Model 1 yields a highly significant parameter estimate for HV, the quadratic counterpart in Model 2 only satisfies the 10\% significance level with the single traffic term being not significant at all. Our results therefore indicate a linear relationship between traffic and the service life of road pavements rather than a quadratic one. The point deterioration elasticity takes the value -0.845 in Model 1 and implies that a one percentage increase in aggregated traffic reduces the service life of the pavement on average by $0.85 \%$. Since the lifespan in Model 2 relies on a linear and quadratic term of the traffic volume, the point elasticity is correspondingly calculated as $\hat{\varepsilon}_{i}=\hat{\beta}_{\log H V}+2 \hat{\beta}_{(\log H V)^{2}} \log \left(H V_{i}\right)$ which results in a mean deterioration elasticity
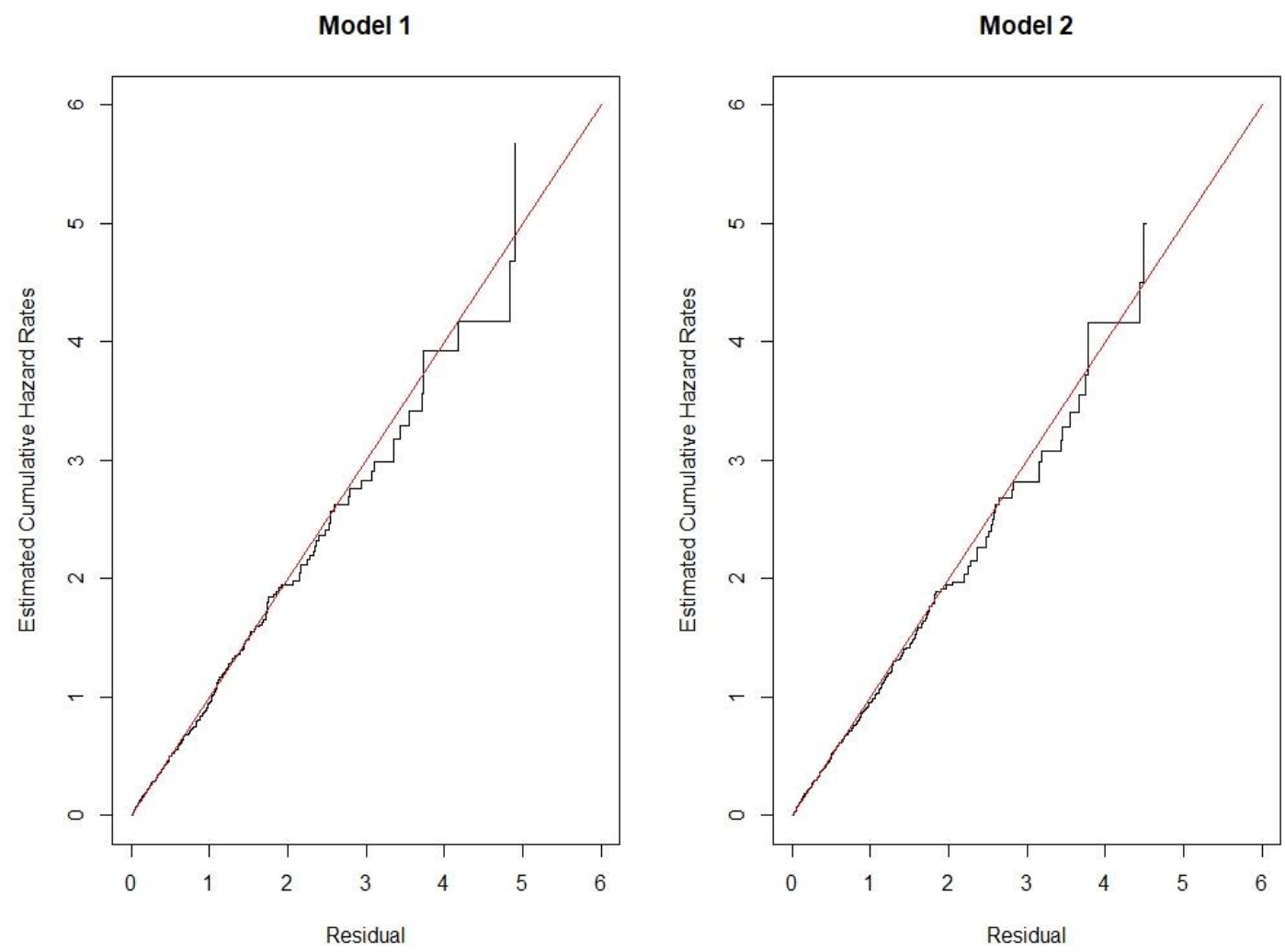

Figure 2: Cox-Snell Residual Specification Test

of -0.89 , similar to the value from Model1. The shape parameter is 2.575 in Model 1 and 2.572 in Model 2 respectively. Also, these values are close to each other and imply that the probability of pavement failure and the need to renew increases more than proportionately over time. The likelihood ratio test indicates that both models perform significantly better than an intercept only 
model. However, the test statistics differ only marginally between the models, which may also be explained by the inclusion of an additional variable in Model 2. In addition, the Cox-Snell residuals specification test (Figure 2) demonstrates no substantial difference in model fit. Overall, we conclude that both models lead to very similar results. However, based on the significance of parameter estimates we select Model 1 as the preferred model and base the computation of marginal costs on the estimates from this model.

Figure 3 depicts the hazard and survival function of our preferred Model 1 . The probability of failure and need for renewal accelerates more than proportionately over time whereby the probability of failure and renewal is relatively low in the first few years, but increases sharply after about 10 years of service. The corresponding strong downward trend in the probability of survival continues until around 30 years, from where on the curve flattens out.
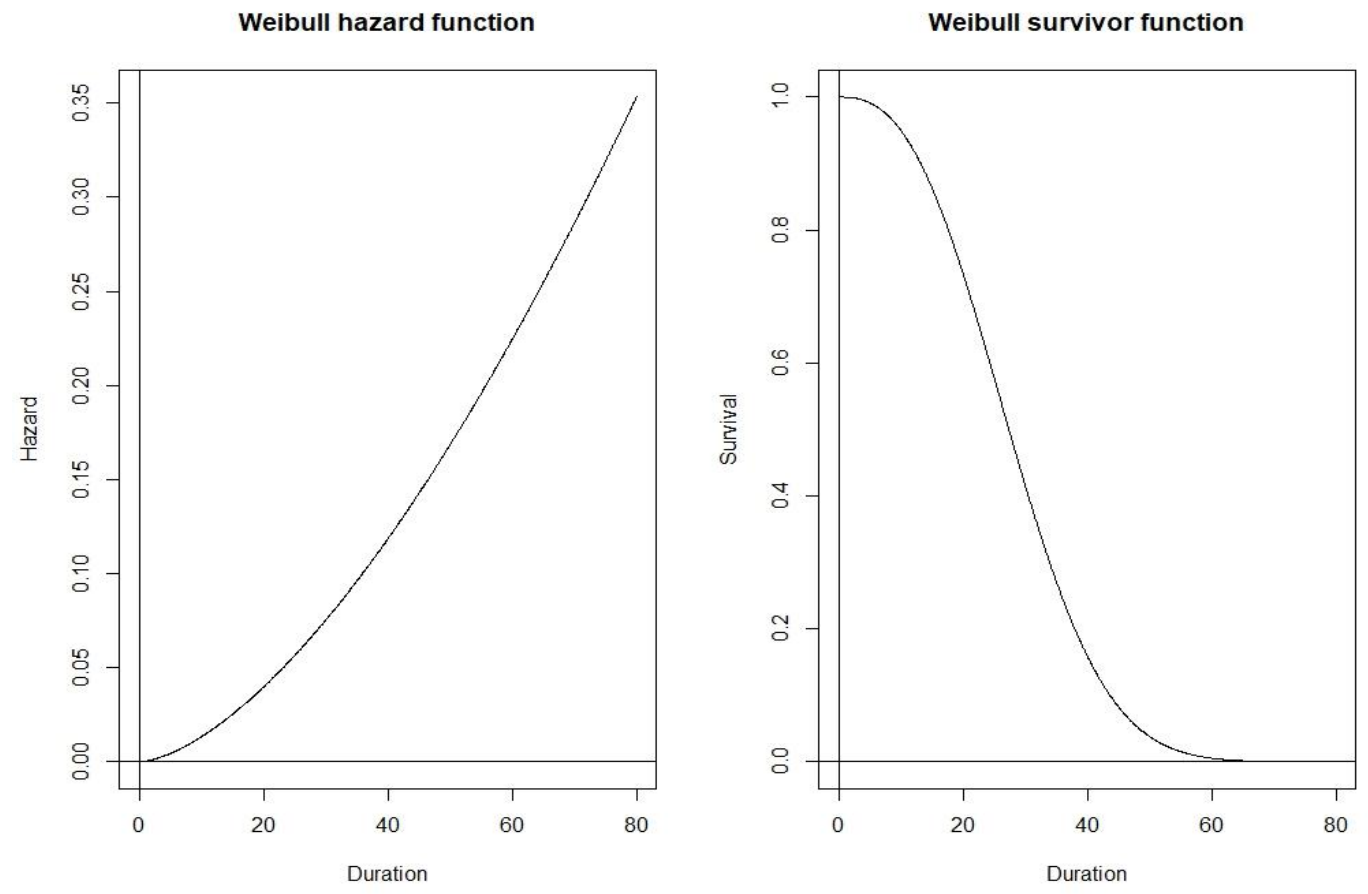

Figure 3: Weibull Hazard and Survivor Functions

Finally, we test the assumption that the survival data is adequately mirrored by a Weibull distribution by comparing the cumulative hazard of Model 1 with the cumulative hazard resulting from a semi-parametric Cox proportional hazard model. The advantage of Cox's PH models lies in its nonparametric approach of estimating survival rates without the necessity of assuming any form of distribution on the baseline hazard function. However, the model still allows the 
functional form of covariates to be estimated parametrically. Thus, if the cumulative hazard based on a Weibull regression reflects the resulting pattern of the Cox proportional hazard estimates, the choice of the Weibull distribution would be supported. Figure 4 shows that in our case the two cumulative hazard functions are relatively similar and support the assumed Weibull distribution.

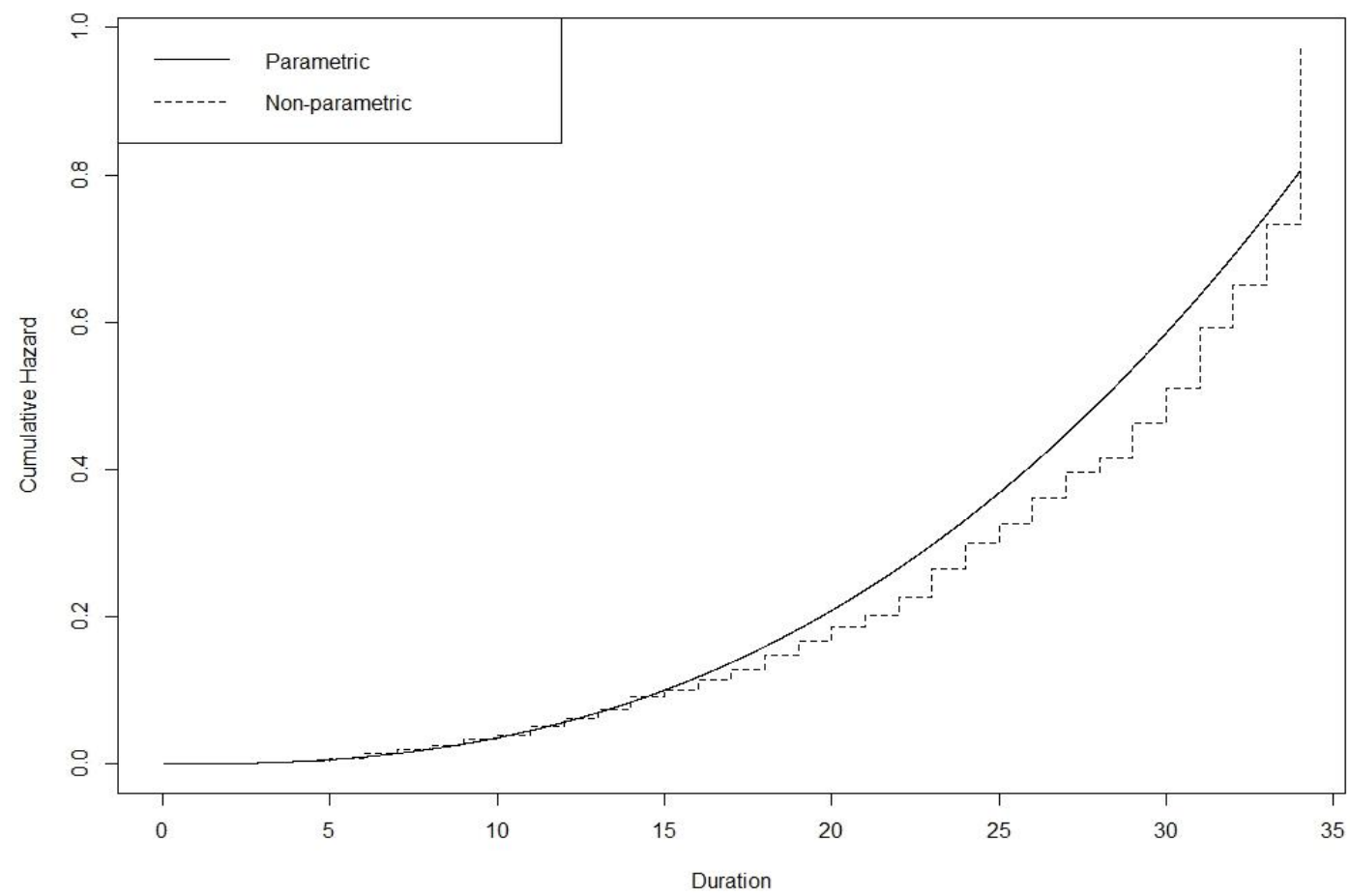

Figure 4: Weibull vs Cox Cumulative Hazard

\subsection{Unobserved Heterogeneity}

So far, we have implicitly assumed that our survivor function is homogeneous over all sections. However, there might exist potential heterogeneity across observations because road sections might not be completely independent and could be clustered such that sections in one cluster suffer from a greater risk of failure than those in a different cluster. The issue of heterogeneity was first addressed by Vaupel et al. (1979) who derived a model that accounts for neglected covariates that possibly affect the hazard of death in the context of a mortality survival analysis. The model is based on an extended proportional hazards model, which includes an additional unobservable random quantity, defined as the frailty. The frailty can be seen as a random effect that is shared within single or clustered observations and that has a multiplicative effect on the 
hazard (Hougaard 1995). In our case, we select a shared regional frailty and accordingly cluster the sections along their regional belonging indicated by the federal state dummies. Thus, the model includes a random effect that accounts for potential heterogeneity of road sections due to regional politics, climate or geographic structures. To identify the frailty correctly, an assumption for the frailty's distribution is necessary. Vaupel et al. (1979) suggest using a gamma distribution because of its advantageous mathematical properties and because the resulting frailty distribution of survivors at any given point in time also follows a gamma distribution with an identical shape but different scale parameter. Moreover, the frailty distribution of failure events also implies a gamma distribution, however, with different shape and scale parameters. Other suggested frailty distributions are the inverse Gaussian, positive stable, compound Poisson or the lognormal distribution (See Duchateau and Janssen 2007). The major factor that is determined by the assumed frailty distribution is the change in conditional frailty densities over time. This is because the degree of homogeneity can change within a population if observations drop out due to the event occurring which in result alters the population structure and given frailty densities. Hougaard (1984) finds that the application of a gamma distribution leads to constant relative frailties over time while, for instance, the use of an inverse Gaussian distribution results in an increasing degree of homogeneity over age. With a view on our underlying data, we do not expect increasing homogeneity across road sections with increasing survival times. Therefore, we assume gamma distributed frailties in our frailty model. Table 3 shows the result of the frailty model. Overall, the coefficients stay very similar to those of the regular Weibull model (Model 1 and Model 2, see table 2). We find the deterioration elasticity to be highly statistically significant and nearly of the same size as in the model without included frailty.

Furthermore, the shape parameter is very close to the estimate from Model 1 and Model 2. A common approach to measure the level of dependence is the use of Kendall's Tau, which for bivariate survival data relates to the frailty variance $\theta$ as $\tau=\frac{\theta}{\theta+2}$ (Oakes 1982). 


\section{Dependent Variable}

\begin{tabular}{ll} 
& Duration \\
\cline { 2 - 2 } & \\
\hline Frailty Variance $(\theta)$ & $\mathbf{0 . 0 2 3}$ \\
& $(0.023)$ \\
Shape & 2.548 \\
& $(0.088)$ \\
\hline
\end{tabular}

$\log H V$

$-0.838 * * *$

(0.057)

Number Lanes

$0.974 * * *$

(0.108)

Period 1

$1.288 * * *$

SMA

$0.577^{* * *}$

(0.115)

Length

$0.054 * * *$

(0.014)

Federal State Dummies

Yes

Renewal Type Dummies

Yes

Observations

1,822

Log Likelihood

$-2158.69$

Kendall's Tau $(\tau)$

0.011

Note: Displayed are the results of a frailty model with a Weibull distributed base line hazard and a gamma distributed frailty. The data is clustered according to a regional variable that indicates the corresponding federal state. Coefficients of the federal state dummies and renewal type dummies are omitted in the output for structural reasons but available on request. Standard Errors are given in parentheses and statistical significance is indicated by asterisks where ${ }^{*} \mathrm{p}<0.1 ;{ }^{* *} \mathrm{p}<0.05 ;{ }^{* * *} \mathrm{p}<0.01$

Hence, a Kendall's Tau equal to zero indicates independent observations. In our case, $\tau$ takes a value of 0.011 and suggests a very low level of heterogeneity across observation clusters. We also test the significance of the frailty variance by a modified likelihood ratio test where the NullHypothesis corresponds to whether the frailty variance is zero. The regular likelihood ratio test can in this case not be applied, since the Null-Hypothesis would be defined at the boundary of the parameter range (see Claeskens et al., 2008). Thus, the family of the log-likelihood differences 
is in this case distributed as $\frac{1}{2} \chi_{0}^{2}+\frac{1}{2} \chi_{1}^{2}$. We find the LR-Test statistic to be equal to 3.38 with a $\mathrm{p}$-value of 0.033 , indicating that the frailty effect is indeed different from zero. Hence, we can observe a minor frailty effect which is statistically significant but does not fundamentally change the regression output compared to a model without frailty. Moreover, the Log Likelihood statistic suggests that the frailty model has a slightly worse fit compared to Model 1 . In conclusion, we do not find any reason to diverge from Model 1 due to unobserved heterogeneity.

\subsection{Marginal Cost Estimates}

The estimates from our Weibull duration model (Model 1) forms one ingredient to the computation of marginal renewal cost. In addition, the average renewal cost and an assumed discount rate is necessary. The average renewal cost per motorway kilometre is estimated at $€ 694,809$ based on the sum of all renewal costs divided by the sum of all renewed kilometres within our full dataset. We apply a discount rate of $3 \%$ which is the official figure used in costbenefit analysis for transport infrastructure projects in Germany. We find a mean marginal cost of $0.026 €$ and a median cost of 0.012 . There is a wide variation within marginal costs when grouped by the corresponding traffic volume quantiles (See Figure 5). This is caused by the fact that renewal costs on low-traffic road sections are distributed among fewer vehicles, while total costs are not necessarily lower than on roads with high traffic frequency. Especially the first quartile includes extreme marginal cost outliers, and an over-proportionally high variance compared to the estimates of the remaining quartiles. Figure 6 visualizes this relationship by plotting the marginal costs against their respective aggregated traffic count.

This finding which is common for all marginal cost studies, suggests that applying a simple average or median marginal cost would lead to distortions, as road sections with low traffic volumes would be treated in the same way as sections with high traffic volumes. Consequently, the average marginal cost would be biased upwards as the average cost per vehicle is significantly higher on low traffic sections. The common approach to address this issue is the use of weights based on traffic volume of each section in relation to total traffic on the overall network. Charging such weighted marginal costs to users guarantees revenue neutrality (see Wheat and Smith, 2008). 


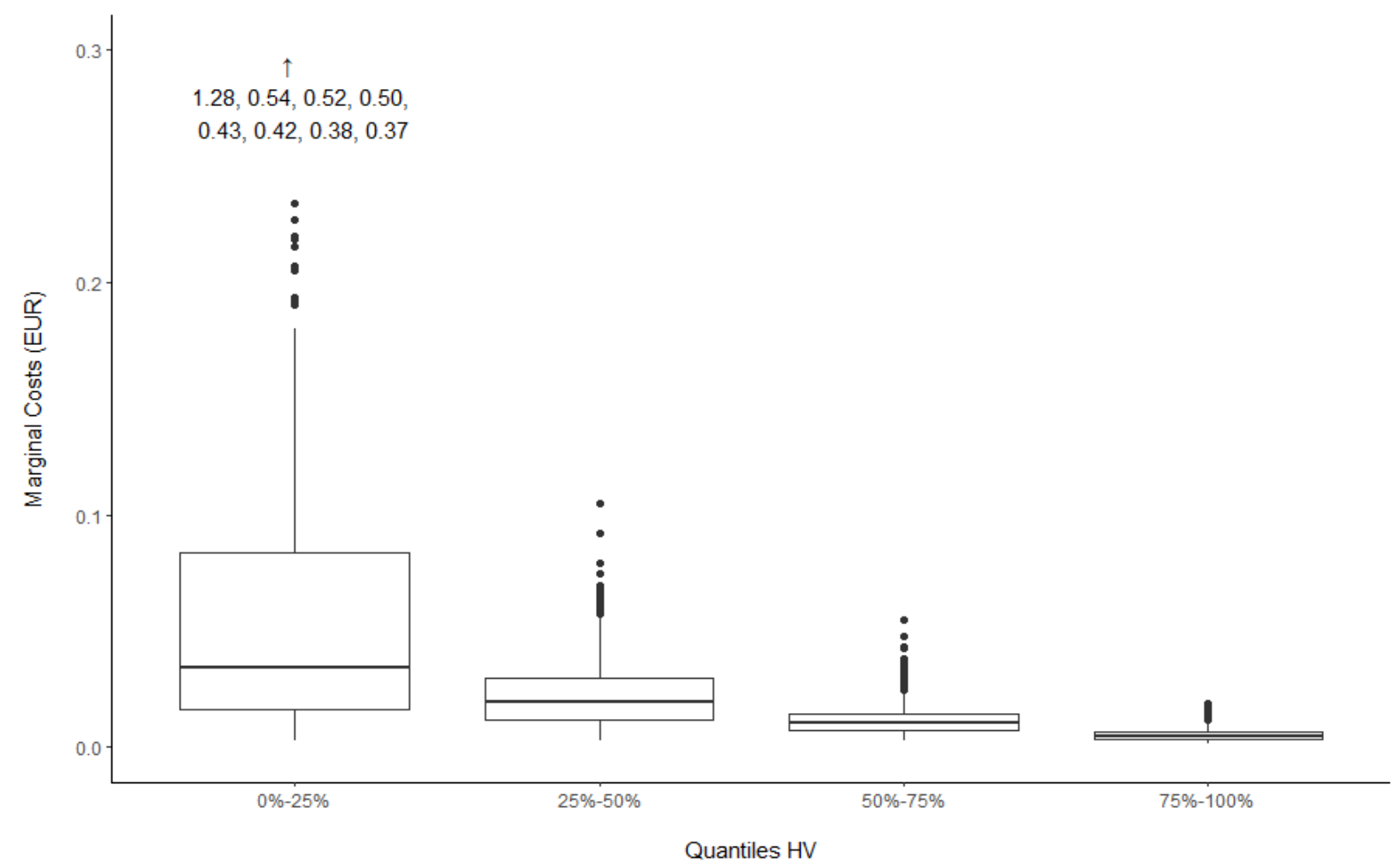

Figure 5: Marginal Costs Estimates on Traffic Quartiles

Note: For a meaningful figure scale, extreme marginal cost outliers within the first traffic quantile are not visualized in the graph but their values are stated on top of the boxplot.

The weighted mean of marginal costs is $€ 0.011$ per heavy vehicle kilometre, e.g. considerably lower than the originally calculated unweighted mean.

Comparing the marginal costs estimated in this paper with other studies faces a several commonly reported problems. To these belong the fact that material and labour costs might vary substantially, geographic, and structural conditions could heavily influence estimates in one country but not in the other, or variables might just be defined in a different way. However, while marginal costs estimates are difficult to compare, the ratio between average costs and marginal costs is less dependent from case-specific issues. Hence, we calculate the ratio between marginal costs due to deterioration and the total average costs for each road section, again weighted by the share of traffic on the respective section. We find that approximately $40 \%$ of the average renewal costs can be linked to the deterioration produced by heavy vehicles. This is considerably 


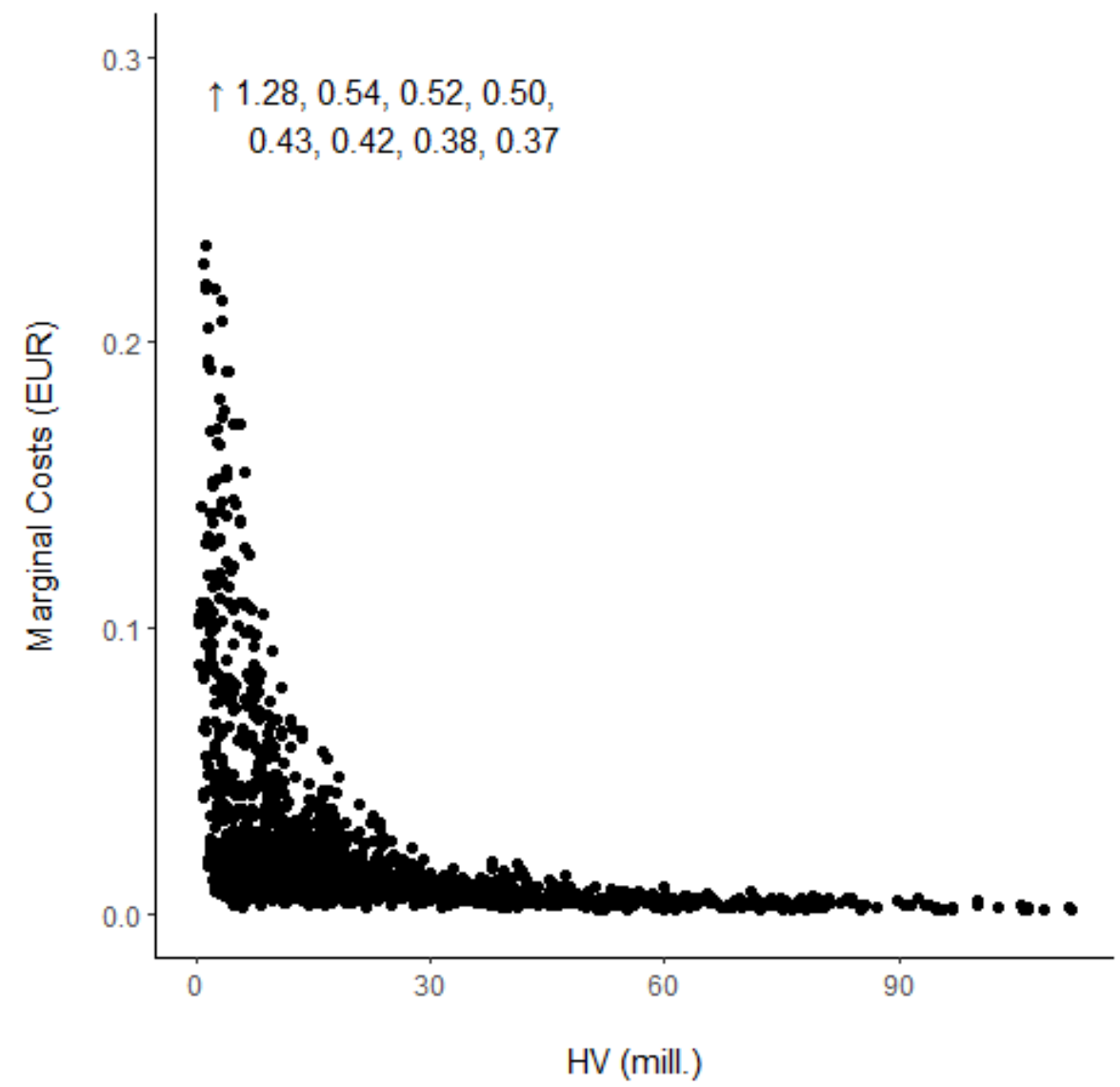

Figure 6: Marginal Costs against Traffic Volume

Note: For better visibility of the graph, extreme marginal cost outliers are not included in the graph, but their values are stated on the upper left corner.

lower than in Newbery's (1985) work but substantially higher than the ratio found in Haraldsson $(2007)^{14}$ based on the same approach except the inclusion of both passenger cars and HGV and covering the whole road network. Interestingly, our value comes close to the one from Lindberg $(2002)^{15}$ who uses a deterministic approach for lifetime finds a ratio between average and marginal costs of $36 \%$. Again, this refers to the whole road network while our study refers to motorway only,

\footnotetext{
14 However, this study reports unweighted marginal costs.

15 However, this study reports unweighted marginal costs.
} 


\section{Conclusion}

In this paper, we have estimated an accelerated failure time model for road pavement based on a comprehensive dataset for West German motorways. Our duration model which is based on a Weibull distribution for the renewal intervals shows a very good overall model fit and highly significant coefficients. The shape parameter of the Weibull function exceeds a value of 2 implying that there is an ageing or weathering effect. The estimates were used in a model that mirrors the relation between traffic pavement costs and traffic load. Our results show - similar to those for Sweden - that the fundamental theorem does not hold for the German motorway network. The deterioration elasticity is different from -1 and higher traffic loads are not the sole factor impacting on shorter pavement lifetimes. Our estimations yield a marginal renewal cost, which makes up approximately $40 \%$ of average renewal cost. This result is of similar magnitude as in Lindberg (2002) with a deterministic lifetime, but considerably higher than Haraldsson (2007) which is based on the same approach except the inclusion of both passenger cars and HGV. It implies that road user charges based on marginal costs will not yield a sufficient revenue to cover total costs. This is an expected outcome and commonly reported in other marginal cost studies.

Directions of further research relate to the econometric core of duration modelling on the one hand and to the general analytical model on the other hand. As regards to the duration model, our current assumption of independence between the lifetimes of recurrent pavement measurements on the same section should be relaxed, as the significant co efficient of our dummy variable for the subsequent re-pavement indicates.

As regards to the analytical model, a future research task is to relax the assumption that only the first overlay cycle is stochastic and shortened due to an increase in traffic load, while all subsequent cycles are treated as fixed. This implies the not realistic consequence that the marginal cost is caused by a temporary shock on an otherwise stable traffic flow. Furthermore, our analysis defines the renewal intervals merely as the time between two overlay renewals (whereby the definition of average costs and thus the derivation of marginal costs also takes into account those costs that arise when a renewal measure includes not only a new overlay but also 
a renewal of other road layers). Renewing base layers and binder courses strengthens the road's durability, which subsequently affects the overall lifetime, and should therefore be accounted for in future analysis.

Finally, a promising direction of further research is to apply the model to the condition measurements from the German road condition measurement project. A comparison of the respective marginal cost with the one obtained in this paper using the actual renewals could give indications on the extent to which the German highway authorities follow a condition-responsive maintenance strategy, and contribute to the debate on under-maintenance of German road infrastructure. In this context it would also be interesting to revisit the magnitude of the external extra vehicle operating costs that a vehicle imposes on subsequent road users due to worsened road conditions. This externality has been derived as negligible in Newbery's (1985) fundamental theorem based on the assumption of a condition responsive maintenance strategy.

\section{References}

Anani, S. B., Madanat, S. M. (2007): Estimation of the marginal cost of highway maintenance under stochastic pavement deterioration. Paper presented at the $6^{\text {th }}$ Conference on Applied Infrastructure Research (Infraday 2007), 1 September 2007, Technical University of Berlin, Berlin. Anani, S. B., Madanat, S. M. (2010a): Estimation of highway maintenance marginal cost under multiple maintenance activities. Journal of transportation engineering, 136(10), 863-870.

Anani, S. B., Madanat, S. M. (2010b): Highway maintenance marginal costs: What if the fourth power assumption is not valid? Transport Policy, 17(6), 486-495.

Andersson, M. (2006): Marginal Cost Pricing of Railway Infrastructure Operation, Maintenance and Renewal in Sweden: From Policy to Practice Through Existing Data, Transportation Research Record: Journal of the Transportation Research Board 1943, Washington, D.C., 1-11.

Andersson, M., Smith, A. S. J., Wikberg, A., Wheat, P. (2012): Estimating the marginal cost of railway track renewals using corner solution models. Transportation Research Part A, 46 (6), $954-$ 964.

Andersson, Mats; Björklund, Gunilla; Haraldsson, Mattias (2016): Marginal railway track renewal costs: A survival data approach. Transportation Research Part A: Policy and Practice 87, S. 6877.

ASTRA (2001): Regionalisierte Langfristprognose des Erhaltungsbedarfs der Bundesautobahnen bis 2015 unter besonderer Berücksichtigung der Controllingfunktion des Bundes bei deren Umsetzung. Projekt-Nr. 28.005/1999 im Auftrage des Bundesministeriums für Verkehr, Bau- und Wohnungswesen. 
BASt. (2015): Zustandsbewertung der ZEB für Bundesfernstraßen ab 2015. Bergisch Gladbach: BASt.

Bhat, C. R. (2020): Chapter 6. Duration Modeling. URL:

www.ce.utexas.edu/prof/bhat/ABSTRACTS/Duration_Modeling.pdf. Accessed on 20 June 2020.

CEC (1998): Fair Payment for Infrastructure Use: A Phased Approach to a Common Transport Infrastructure Charging Framework in the EU, EU White Paper. COM (98) 466 final, 22 July 1998.

CEC (2001): European Transport Policy for 2010: Time to decide, EU White Paper. COM (2001) 370 final, 12 September 2001, Brussels.

Claeskens, G., Nguti, R. \& Janssen, P. (2008): One-sided tests in shared frailty models. TEST 17, 69-82.

Cragg, J. G. (1971): Some statistical models for limited dependent variables with application to the demand for durable goods. Econometrica: Journal of the Econometric Society, 829-844.

Duchateau, Luc; Janssen, Paul (2007): The frailty model. Springer Science \& Business Media.

Dupuy, J. F. (2014): Accelerated Failure Time Models: A Review. International Journal of Performability Engineering, 10(1).

Directive 2001/14/EC of the European Parliament and of the Council of 26 February 2001 on the allocation of railway infrastructure capacity and the levying of charges for the use of railway infrastructure and safety certification

Fitschen, Arnd; Nordmann, Hartwig (2012): Verkehrsentwicklung auf Bundesfernstraßen 2010.

Haraldsson, Mattias (2007): The marginal cost for pavement renewal: a duration analysis approach. Statens väg-och transportforskningsinstitut.

Hensher, D. A., \& Mannering, F. L. (1994): Hazard-based duration models and their application to transport analysis. Transport Reviews, 14(1), 63-82.

Highway Research Board (1961): The AASHO-Road-Test - History and Description of Project. Special Report 61 A, Washington D.C.

Hofko, B., Blab, R., Karlsson, R. (2009): "Deliverable D7. outline of a new empirical road damage experiment."

Hougaard, Philip (1984): Life table methods for heterogeneous populations: Distributions describing the heterogeneity. Biometrika 71 (1), S. 75-83. DOI: 10.1093/biomet/71.1.75.

Hougaard, Philip (1995): Frailty models for survival data. Lifetime data analysis 1 (3), S. 255-273. Jiang, C., Bhat, C. R., \& Lam, W. H. (2020): A bibliometric overview of Transportation Research Part B: Methodological in the past forty years (1979-2019). Transportation Research Part B: Methodological, 138, 268-291 
Klein, John P.; Moeschberger, Melvin L. (2006): Survival analysis: techniques for censored and truncated data: Springer Science \& Business Media.

Lindberg, G., (2002): Marginal Costs of road maintenance for heavy goods vehicles on Swedish roads. Annex A2 of Deliverable 10 of the UNITE project, Linköping.

Link, H. (2006): 'An econometric analysis of motorway renewal costs in Germany', Transportation Research Part A, 40, 19-34.

Link, H. (2015): Road and rail infrastructure costs. In Nash, C. (Ed.). (2015). Handbook of research methods and applications in transport economics and policy. Edward Elgar Publishing.

Maerschalk, G., Kause, G., Hinsch, K. (2017): Erhaltungsbedarfsprognose (BVWP) 2016 - 2030 der Bundesfernstraßen. Schlussbericht. Online verfügbar unter https://www.bmvi.de/SharedDocs/DE/Anlage/StB/erhaltungsbedarfsprognoseschlussbericht.pdf?_blob=publicationFile.

Marti, M., Neuenschwander, R., Walker, P. (2009): Tack maintenance and renewal costs in Switzerland. Annex 1B to Deliverable D8, Rail Cost Allocation for Europe. CATRIN (Cost Allocation of Transport Infrastructure). EU-Project funded by Sixth Framework Programme. VTI, Stockholm. Mendes, A. C., \& Fard, N. (2014): Accelerated failure time models comparison to the proportional hazard model for time-dependent covariates with recurring events. International Journal of Reliability, Quality and Safety Engineering, 21(02), 1450010.

Miller, E. V. (1953):"The WASHO road test." Highway Res Abstracts Hwy Res Board.

Mireh, S., Khodadadi, A., Haghighi, F. (2019): "Copula-based reliability analysis of gamma degradation process and Weibull failure time." International Journal of Quality \& Reliability Management.

Newbery, D. M. (1985): The Fundamental Theorem of Road User Charges. No. 59. CEPR Discussion Papers.

Newbery, D. M. (1988): Road Damage externalities and Road User Charges. Econometrica 56, 295316.

Newbery, D. M. (1989): Cost Recovery from Optimally Designed Roads. Economica 56, 165-185. Oakes, David (1982): A model for association in bivariate survival data. Journal of the Royal Statistical Society: Series B (Methodological) 44 (3), S. 414-422.

Ozbay, K., Bartin, B. and Berechman, J. (2001): ,Estimation and evaluation of full marginal costs of highway transportation in New Yersey'. Journal of Transportation Statistics, 4, No. 1.

Peng, T., Wang, X., Chen, S. (2013): Pavement performance prediction model based on Weibull distribution. Applied Mechanics and Materials, Vol. 378, 61-64.

Prozzi, J.A, Madanat, S. (2000): "Using duration models to analyze experimental pavement failure data". Transportation Research Record 1699.1 (2000): 87-94. 
Prozzi, J. A., Madanat, S. M. (2004): Development of pavement performance models by combining experimental and field data. Journal of Infrastructure Systems, 10(1), 9-22.

Rosauer, Verena (2010): Abschätzung der herstellungsbedingten Qualität und Lebensdauer von Asphaltdeckschichten mit Hilfe der Risikoanalyse. TU Darmstadt.

Small, K. A., Winston, C. (1988): 'Optimal highway durability'. The American Economic Review, 78(3), 560-569.

Small, K. A., \& Winston, C. C. \& CA EVANS (1989): Road work: a new highway pricing and investment policy. The Bookings Institution, Washington.

Vaupel, J. W., Manton, K. G., \& Stallard, E. (1979): The impact of heterogeneity in individual frailty on the dynamics of mortality. Demography, 16(3), 439-454.

Wheat, P., Smith, A. (2008): 'Assessing the Marginal Infrastructure Maintenance Wear and Tear Costs for Britain's Railway Network'. Journal of Transport Economics and Policy, 42(2), 189-224.

Williams, S., Lee, A. (1958): "LOAD-DEFLECTION STUDY OF SELECTED HIGH TYPE FLEXIBLE PAVEMENT IN MARYLAND." Highway Research Board Bulletin 177. 